\title{
ANÁLISE DA VARIABILIDADE TÉRMICA DA CIDADE DE PARANAGUÁ-PR PARA APLICAÇÃO EM ESTUDOS SOBRE A PROLIFERAÇÃO DO AEDES AEGYPTI
}

\author{
THERMAL VARIABILITY ANALISYS OF THE CITY OF PARANAGUÁ-PR FOR APPLICATION IN STUDIES ON \\ THE PROLIFERATION OF AEDES AEGYPTI
}

\author{
João André Martinson Salesbram¹, Wilson Flávio Feltrim Roseghini \\ 1 Universidade Federal do Paraná" (UFPR), Paraná, PR, Brasil
}

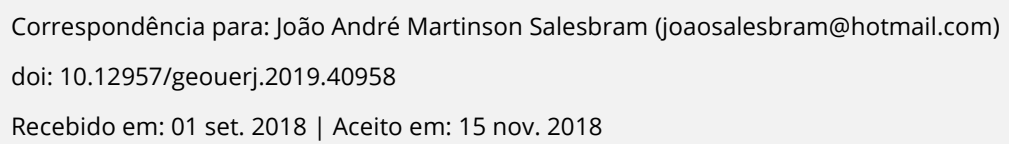

\section{SCREENED BY $\sqrt{ }$ iThenticate $^{\circ}$}

\section{RESUMO}

Previsões do IPCC (2013) apontam para um aumento na temperatura média global até o final do presente século entre $1,8^{\circ} \mathrm{C}$ e $4,0^{\circ} \mathrm{C}$, acarretando em desastres naturais, e também de epidemias, como a dengue, principalmente nas zonas tropicais do planeta. Deste modo, o presente artigo tem por objetivo analisar a variabilidade da temperatura na cidade de Paranaguá/PR, visando a aplicação em futuros estudos sobre a proliferação do mosquito Aedes aegypti. A cidade passou a apresentar epidemias de dengue em períodos recentes, motivando assim a investigação, no sentido de verificar se houveram alterações térmicas que pudessem favorecer o vetor da doença. Foram analisados dados decadais, anuais e mensais de temperatura da estação meteorológica do INMET em Paranaguá e correlacionados com o Índice de Oscilação Sul e o Índice de Temperatura da Superfície do Mar no Atlântico Sul. As analises demonstraram uma alta correlação através de diferentes métodos estatísticos. Também foi detectado um aumento de $0,8^{\circ} \mathrm{C}$ na temperatura média no período analisado, o que não significa afirmar que este é o único motivo, em especial da grande epidemia ocorrida entre 2014/2015 na cidade de Paranaguá/PR, necessitando de novos estudos que visem a inclusão de outros parâmetros a serem analisados.

Palavras-chave: Clima; Epidemia; Dengue; Variabilidade; Paranaguá..

\section{ABSTRACT}

IPCC forecasts (2013) point to an increase in the global average temperature until the end of this century between $1.8^{\circ} \mathrm{C}$ and $4.0^{\circ} \mathrm{C}$, resulting in natural disasters, as well as epidemics such as dengue, mainly in the tropics of the planet. Thus, the present article aims to analyze the temperature variability in the city of Paranaguá / PR, aiming at the application in future studies on the proliferation of Aedes aegypti mosquito. The city began to present dengue epidemics in recent periods, thus motivating the investigation, in order to verify if there were thermal alterations that could favor the vector of the disease. Annual, annual and monthly temperature data from the INMET meteorological station in Paranaguá were analyzed and correlated with the South Oscillation Index and the South Atlantic Sea Surface Temperature Index. Analyzes showed a high correlation through different statistical methods. An increase of $0.8^{\circ} \mathrm{C}$ in the mean temperature was also detected in the period analyzed, which is not to say that this is the only reason, especially for the great epidemic that occurred between 2014/2015 in the city of Paranaguá / PR, requiring new studies that aim to include other parameters to be analyzed

Keywords: Climate; Epidemic; Dengue; Variability; Paranaguá

\section{INTRODUÇÃO}


A elevação da temperatura global vem efetivamente ocorrendo, mas é necessário se ter uma investigação abrangente das causas desse aumento, e não levar em consideração somente a ação antrópica, mas também, os processos de macro-escala, incluindo os da esfera geológica e astronômica.

A mudança climática é um processo dinâmico complexo que envolve mais do que a simples elevação da média térmica, mesmo porque o clima não se define só pela temperatura. Contudo, a reação em cadeia que se estabelece a partir do aquecimento deve ser avaliada em profundidade (CONTI, 2005).

Parâmetro indispensável para a análise da mudança climática global, a temperatura, vem sendo monitorada a décadas. Segundo o Quarto Relatório do Intergovernmental Panel on Climate Change, o aumento da temperatura global previsto é de $1,8^{\circ} \mathrm{C}$ à $4,0^{\circ} \mathrm{C}$ até o final do século XXI (IPCC, 2013). Tanto para o IPCC, quanto para o PBMC (Painel Brasileiro de Mudanças Climáticas), este aumento da temperatura intensificará os eventos climáticos catastróficos globais, tais como furacões, terremotos, secas, chuvas torrenciais, entre outros.

Além dos eventos climáticos, as doenças neotropicais também poderão ser potencializadas com a elevação da temperatura especialmente nos trópicos, neste contexto está inserido a dengue, classificada como uma arbovirose, a doença é transmitida pelo mosquito Aedes aegypti ao ser humano, sendo encontrado nas regiões tropicais do planeta.

Os primeiros registros no Brasil são datados do século XIX, onde sua disseminação era através de embarcações no período colonial (CATÃO, 2011). Há relatos de casos no começo do século XX, por volta do ano de 1920, e posteriormente até a década de 1970 não ouve nenhum caso confirmado, sendo a doença considerada erradicada nesse período (FERREIRA, 2016). Sua reintrodução se deu no ano de 1976 (MELO, 2009), e logo se espalhou para outros estados, tendo como causas a falha na vigilância epidemiológica e mudanças causadas pela urbanização crescente no período (MELO, 2009). Na década de 1980, as primeiras epidemias foram registradas no país (HONÓRIO, 2009), sendo a primeira no estado de Roraima, registrando 11 mil casos da doença. No mesmo ano quase todas as cidades litorâneas já registravam a presença do mosquito, que nos anos seguintes se expandiu para o 
interior do país devido a fragilidade dos serviços de saúde e aliado ao aumento da população e o consequente aumento de resíduos sólidos, que descartados a céu aberto servem de criadouros do mosquito (MENDONÇA et al, 2009).

O estado do Paraná é o estado da região sul que mais notifica casos de dengue. Os primeiros casos notificados foram em 1991, sendo alóctones, e em 1995 foram confirmados os primeiros casos autóctones da doença. Entre 1995 e 2003, a dengue atingiu quase todos os estados do Paraná, tendo as cidades de Londrina, Foz do Iguaçu e Maringá, como as cidades que apresentaram o maior número de casos (ARAUJO, 2013). Duque et al (2010) indica que no período de 1995 a 2003 no estado do Paraná ocorreram três eventos de epidemia, com picos de incidência nos biênios 1995-96, 2002-03 e 2006-07.

Levando em consideração que a cidade de Paranaguá/PR tornou-se epidêmica recentemente, foram obtidos dados sobre os casos de dengue na cidade de Paranaguá/PR, a título de quantificação.

Os dados obtidos mostram que Paranaguá tem registro de casos de dengue a partir de 2005, ano em que foram confirmados seis casos alóctones. Nos anos subsequentes, 2010, 2011 e 2012, também registraram casos alóctones até que no verão 2013/2014 teve-se a confirmação do primeiro caso autóctone.

No verão 2015/2016 foi confirmada oficialmente a epidemia de dengue, registrando 15.712 notificações de casos autóctones da doença (tabela 1).

\begin{tabular}{cccc}
\hline \multicolumn{4}{c}{ HISTÓRICO DOS CASOS DE DENGUE NA CIDADE DE PARANAGUÁ/PR } \\
\hline ANO & AUTÓCTONES & ALÓCTONES & TOTAL \\
2005 & & 6 & 6 \\
2010 & & 9 & 9 \\
$2011 / 2012$ & & 4 & 4 \\
$2013 / 2014$ & 1 & 1 & 2 \\
$\mathbf{2 0 1 5} / \mathbf{2 0 1 6}$ & $\mathbf{1 5 . 7 1 2}$ & $\mathbf{6 8 0}$ & $\mathbf{1 6 . 3 9 2}$ \\
\hline
\end{tabular}

Tabela 1. Histórico de casos autóctones e alóctones confirmados de dengue para a cidade de Paranaguá/PR 
Deste modo, o presente artigo tem por objetivo analisar a variabilidade térmica da cidade de Paranaguá para aplicações posteriores no estudo da proliferação do vetor.

\section{CARACTERIZAÇÃO DA ÁREA DE ESTUDO}

O município de Paranaguá situa-se à sudeste do estado do Paraná, entre as latitudes $25,365^{\circ} \mathrm{S}$ e $25,735^{\circ} \mathrm{S}$ e longitude $48,706{ }^{\circ} \mathrm{W}$ e $48,277^{\circ} \mathrm{W}$, localizando-se assim na fachada Atlântica Sul do Brasil (MELLO et al, 2017) (figura 1).

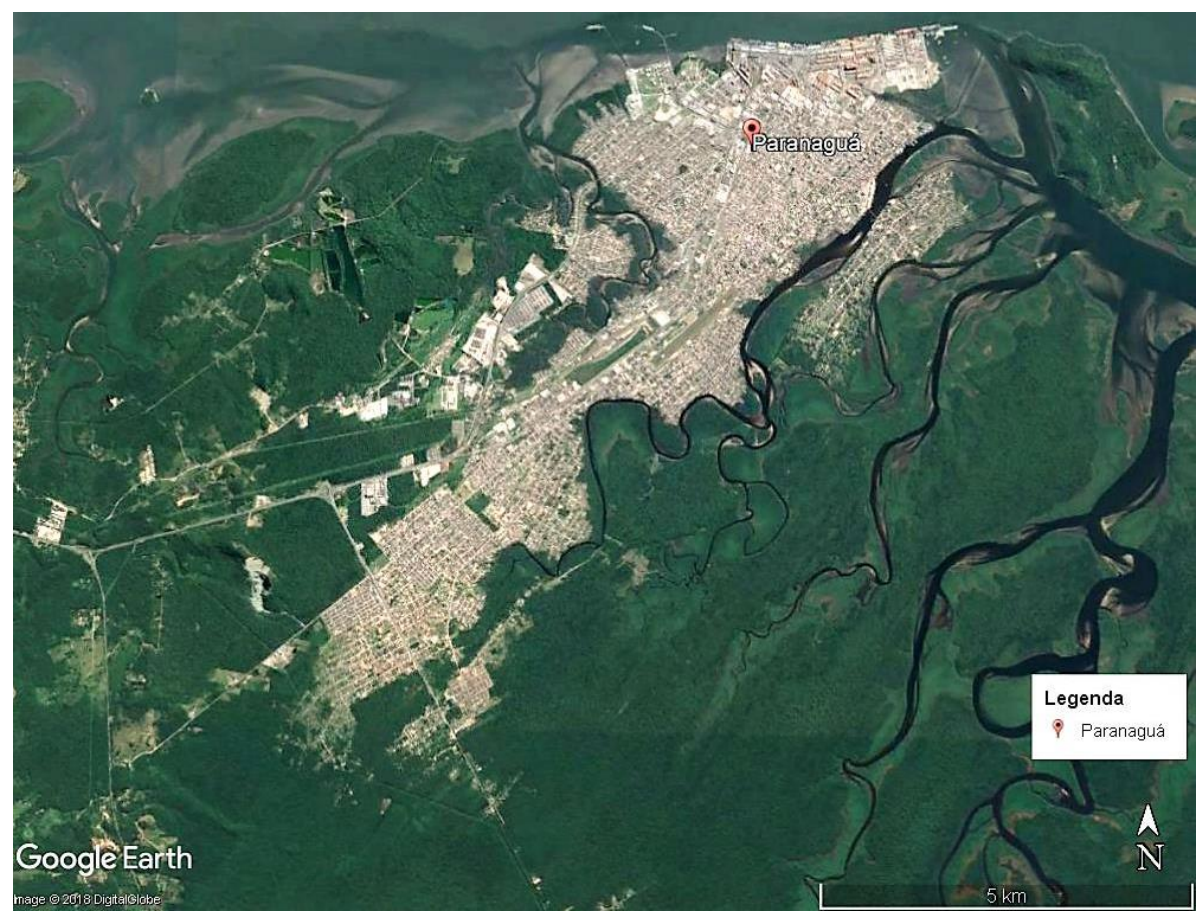

Figura 1. Localização da cidade de Paranaguá, área foco do estudo

O território está dividido em duas zonas distintas, a Unidade da Serra do Mar e a Unidade da Planície Litorânea. A altitude vária desde o nível do mar até altitudes que superam os 1.000 metros, na Serra da Prata (MELLO et al, 2017).

A Serra do Mar paranaense apresenta características distintas das de outros estados brasileiros, por não constituir apenas uma serra de borda de planalto ou escarpa, mas também possui locais originados principalmente por erosão diferencial. Geologicamente é formada por terrenos pré-cambrianos que são 
pertencentes ao complexo cristalino brasileiro, sendo constituída por gnaisses e granitos intensamente desgastados (BIGARELLA, 2001).

A Planície Litorânea possui de 10 a 20 KM de largura, e atinge no máximo 50 KM na baia de Paranaguá. É constituída de formações arenosas, paludais terrestres, manguezais, e nas proximidades do complexo cristalino por terrenos de aluviões terrestres. A altitude varia de zero a $10 \mathrm{~m}$ sobre 0 nível do mar, e nos pontos mais interiores atinge 20 m de altitude (BIGARELLA, 2001).

Autores como Bianchin (2013) e Sereda (2008), levam em consideração a classificação de Koeppen, onde o clima da planície litorânea do estado do Paraná, e que estende-se até 700 metros de altitude na Serra do Mar é classificado como sendo do tipo Cfa (Subtropical Úmido - Mesotérmico), com médias nos meses de verão superiores a $22^{\circ} \mathrm{C}$, e nos meses de inverno com médias abaixo dos $18^{\circ} \mathrm{C}$, sem estação seca definida e com verões quentes e tendencialmente mais chuvosos, e geadas menos frequentes no inverno.

Acima dos 700 metros, o clima passa para Cfb (Subtropical Úmido - Mesotérmico com verão fresco), com precipitação mais abundante, onde a temperatura média no verão não ultrapassa os $22^{\circ} \mathrm{C}$ e a mínima fica abaixo dos $18^{\circ} \mathrm{C}$ (VANHONI e MENDONÇA, 2008). Ainda segundo Sereda (2008) o clima da planície litorânea onde a cidade de Paranaguá está inserida é considerado Af, sem estação seca definida e isento de geadas.

\section{MATERIAIS E MÉTODOS}

Realizou-se uma análise dos dados históricos de temperatura da Estação Meteorológica Convencional de Paranaguá (EMCP), para o período de 1961-2016, disponíveis no banco de dados do INMET (Instituto Nacional de Meteorologia).

A partir dos dados obtidos da Estação Meteorológica Convencional de Paranaguá, foram construídos gráficos, através do Software Microsoft Excel 2013, a fim de analisar a variabilidade da temperatura 
no período analisado. Primeiro obteve-se gráficos com as médias da temperatura máxima e também da mínima, assim como da temperatura compensada média decadal. Da mesma forma, os mesmos parâmetros foram analisados para os gráficos anuais. Por último, foram obtidos gráficos de temperatura compensada média mensais, finalizando assim a análise dos dados da Estação Meteorológica Convencional de Paranaguá.

Para fins de correlação, também se analisou dados disponíveis do Índice de Oscilação Sul - Southern Oscillation Index (SOI), com objetivo de correlacionar a variabilidade climática da área com os eventos de El Niño - Oscilação Sul (ENOS), permitindo assim verificar a influência da circulação de grande escala. O IOS é um índice gerado a partir da diferença de pressão atmosférica existente entre duas localidades no Pacífico (Tahiti e Darwin) que representam a teleconexão oceano-atmosfera resultante das alterações da Temperatura da Superfície do Mar (TSM) decorrentes dos eventos ENOS.

A fonte de dados do índice utilizada para este estudo foi cedida pelo Bureau de Meteorologia da Austrália (BOM).

Quanto aos dados de temperatura da superfície do mar no Atlântico sul - Tropical Southern Atlantic Temperature index (TSA) foram utilizados dados disponíveis no período 1982-2013.

As análises estatísticas utilizadas para tratamento dos dados SOI e TSA foram, correlação de Pearson e $\mathrm{R}^{2}$, utilizando se do Software Microsoft Excel 2013. O intuito dessas analises, foi verificar se há a interferência desses dois sistemas no clima da área foco do estudo.

Os números de casos de dengue foram obtidos a partir do banco de dados da SESA Paraná (Secretaria de Estado da Saúde).

\section{RESULTADOS E DISCUSSÕES}

\section{Análise decadal}


No período analisado, a década de 2010 demostrou-se como sendo a mais quente na média, com janeiro e fevereiro apresentando as temperaturas mais elevadas do período, $26,1^{\circ} \mathrm{C}$ e $26,2^{\circ} \mathrm{C}$ respectivamente. Nos meses de março e abril, os anos 2000 tiveram as temperaturas médias mais altas, apresentando $25,3^{\circ} \mathrm{C}$ e $23,2^{\circ} \mathrm{C}$ respectivamente, assim como também em junho e julho, com $18,5^{\circ} \mathrm{C}$ e $17,9^{\circ} \mathrm{C}$ respectivamente. Os anos de 2010 , novamente apresentou-se tendo as temperaturas médias mais altas nos meses de agosto, setembro, outubro e dezembro. Por outro lado, as médias mais baixas para o período ficaram entre a década de 1980 , com $17,2^{\circ} \mathrm{C}$ em junho e a década de 1990 com $16,7^{\circ} \mathrm{C}$ em julho (figura 2-A). Quando se comparou a temperatura compensada média entre as décadas, o resultado mostrou um aumento de $0,8^{\circ} \mathrm{C}$ no período analisado, partindo de $21,2^{\circ} \mathrm{C}$ na década de 1960 e chegando a $22,0^{\circ} \mathrm{C}$ na década de 2010 (figura 2-B).
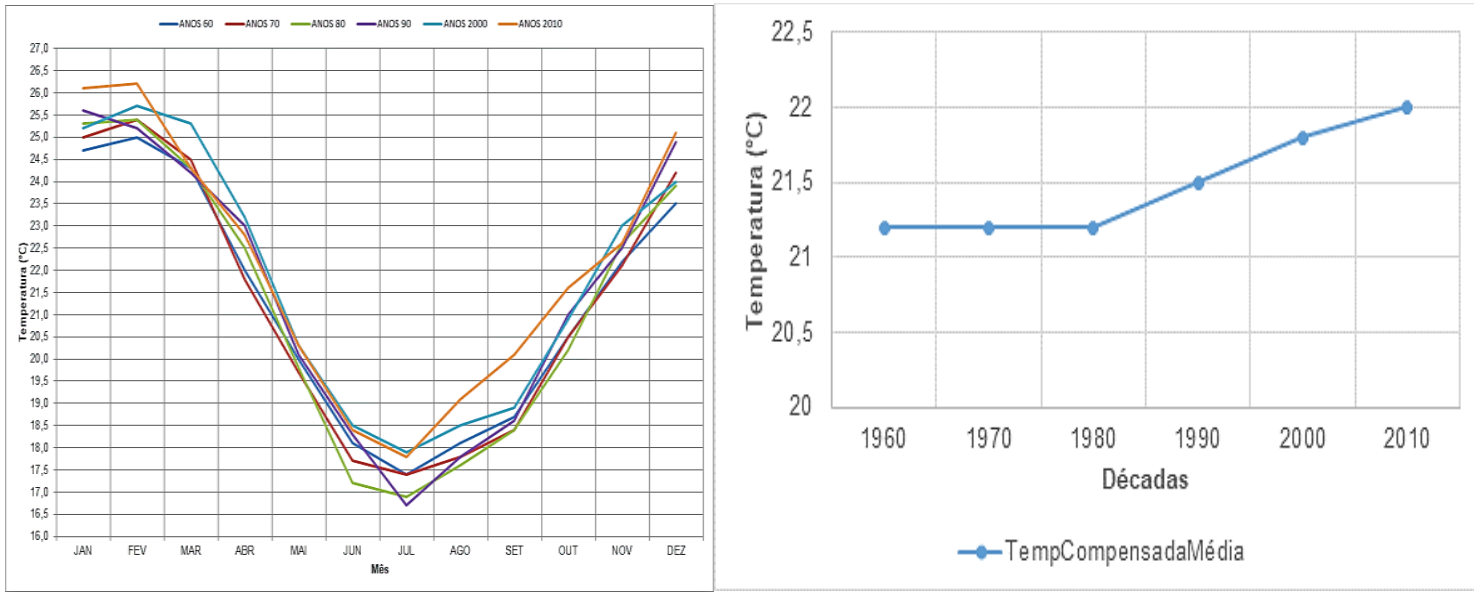

Figura 2/A. Análise da temperatura média decadal $\left({ }^{\circ} \mathrm{C}\right)$ para a cidade de Paranaguá/PR, dos anos de 1960 até os anos de 2010, a partir de dados da Estação Meteorológica Convencional de Paranaguá (EMCP). 2/B- Temperatura compensada média decadal $\left({ }^{\circ} \mathrm{C}\right)$ para a cidade de Paranaguá/PR, dos anos de 1960 até os anos de 2010, a partir de dados da Estação Meteorológica Convencional de Paranaguá (EMCP).

O clima é controlado por diversos fatores, e a ação antrópica (ação do homem) é uma delas (PBMC, 2015). 0 aumento da temperatura global tem sido causado pela ação antrópica, com maior intensidade, desde o começo do século XX. Segundo o $5^{0}$ Relatório do IPCC, nos últimos 50 anos ouve um aumento da temperatura média global de $0,13^{\circ} \mathrm{C}$ por década (IPCC, 2013).

Projeções e simulações geradas por modelos do PBMC (2015), que levam em consideração os diferentes cenários de emissões globais de gases do efeito estufa, preveem um aumento médio na 
temperatura de $0,5^{\circ}$ a $1^{\circ} \mathrm{C}$ até os anos $2040,1,5^{\circ} \mathrm{C}$ a $2^{\circ} \mathrm{C}(2041-2070)$ e $2,5^{\circ}$ a $3^{\circ} \mathrm{C}(2071-2100)$, para o Bioma Mata Atlântica, porção Sul/Sudeste (região correspondente onde a área de estudo está inserida), com previsão também de aumento da pluviosidade no mesmo período.

Ao analisar-se a tendência e variabilidade da temperatura, fica evidenciado o aumento médio principalmente nas últimas três décadas, na cidade de Paranaguá/PR. Conhecendo a cidade, e o seu crescimento, tanto em número populacional quanto em infraestrutura, das últimas décadas, principalmente por se tratar de uma cidade portuária, pode-se entender um pouco das causas deste aumento, principalmente devido a ação antrópica, que já é sabido, devido a estudos comprobatórios como os do IPCC, PBMC, Conti (2005) E Mendonça et al (2009), de que a ação humana vem interferindo no clima.

Se este aumento na temperatura continuar nos próximos anos, como apontam as análises decadais, a cidade de Paranaguá poderá sofrer consequentemente com mais eventos epidêmicos de igual ou até mesmo de maior proporção. Além do fator temperatura, por se tratar de uma cidade litorânea, outro fator que deverá colaborar, no possível aumento de casos é o aumento da pluviosidade, que na região já é bastante elevado durante o ano, conforme já foi verificado no relatório do PBMC.

\section{Análise anual}

Quando se analisa as temperaturas anualmente, e suas linhas de tendência, percebe-se que se mantiveram praticamente estáveis às máximas médias, porem em alguns anos apresentaram valores muito abaixo destoando dos demais, como é o caso dos anos de $1990\left(22,1^{\circ} \mathrm{C}\right), 1997\left(21,8^{\circ} \mathrm{C}\right), 2007$ $\left(18,4^{\circ} \mathrm{C}\right), 2013\left(18,9^{\circ} \mathrm{C}\right)$ e $2016\left(20,9^{\circ} \mathrm{C}\right)$. Ao contrário, as mínimas médias tiveram um aumento no período analisado de $0,8^{\circ} \mathrm{C}$, saindo de $18,7^{\circ} \mathrm{C}$ no ano de 1961 e atingindo $19,5^{\circ} \mathrm{C}$ em 2015 , e em 1971 apresentou a menor mínima média $\left(13,8^{\circ} \mathrm{C}\right)$, devido ao rigoroso inverno apresentado naquele ano (figura 3-A). Os anos que apresentaram as médias mais quentes foram $1961\left(22,1^{\circ} \mathrm{C}\right), 1977$ $\left(22,2^{\circ} \mathrm{C}\right), 1981\left(22,1^{\circ} \mathrm{C}\right), 2002\left(22,3^{\circ} \mathrm{C}\right)$ e $2014 / 15\left(22,5^{\circ} \mathrm{C}\right)$, em contrapartida os anos mais frios foram $1962 / 68 / 88\left(20,6^{\circ} \mathrm{C}\right), 1964\left(20,5^{\circ} \mathrm{C}\right)$ e $1965\left(20,1^{\circ} \mathrm{C}\right)$ (figura $\left.3-\mathrm{B}\right)$. 

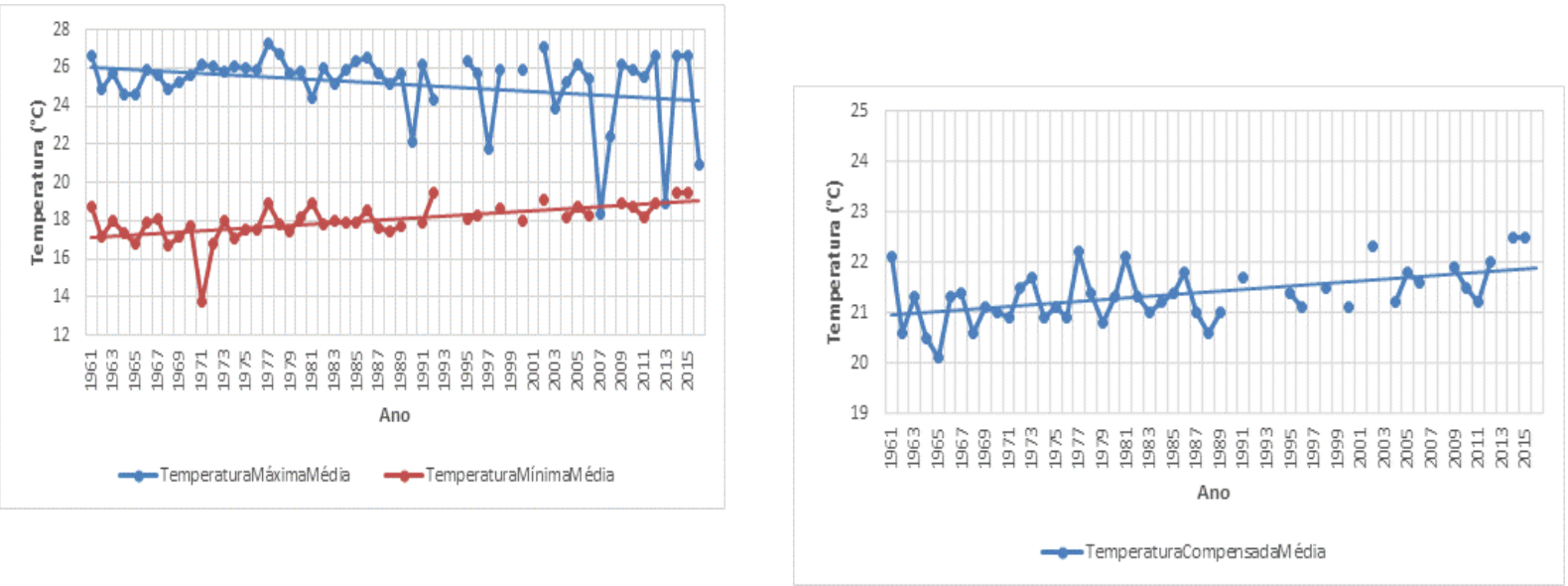

Figura 3/A. Histórico anual da variação de temperatura máxima e mínima média $\left({ }^{\circ} \mathrm{C}\right)$ para a cidade de Paranaguá/PR no período compreendido entre 1961-2016, a partir de dados da Estação Meteorológica Convencional de Paranaguá (EMCP) 3/B. Histórico anual da variação de temperatura compensada média $\left({ }^{\circ} \mathrm{C}\right)$ para a cidade de Paranaguá/PR no período de 1961 à 2016, a partir de dados da Estação Meteorológica Convencional de Paranaguá (EMCP).

Quando se analisa as temperaturas máximas e mínimas medias do ano de 2015, onde ocorreu a epidemia, pode-se observar que a máxima registrada foi de $26,6^{\circ} \mathrm{C}$, mantendo-se na média da série histórica. Já a temperatura mínima média registrou $19,5^{\circ} \mathrm{C}$, sendo ao lado de 2014 , os anos em que as temperaturas mínimas e também a média anual obtiveram os maiores valores para a série histórica analisada, o que mostra uma das causas da epidemia, já que o vetor da dengue tem a sua capacidade de reprodução potencializada principalmente em períodos que a temperatura mínima e a média estão acima dos $18^{\circ} \mathrm{C}$. Mas esse fato não pode ser considerado como o principal motivo da epidemia, já que outros anos apresentaram temperaturas médias parecidas com a do ano 2015, como é o caso de 1961 , 1977, 1981 e 2002 que não apresentaram casos autóctones da doença, tão pouco epidemia.

Desde que os primeiros casos de dengue no estado do Paraná foram registrados no ano de 1995 até o ano de 2014, a cidade de Paranaguá sempre registrou temperaturas médias anuais entre $21^{\circ} \mathrm{C}$ e $22,5^{\circ} \mathrm{C}$ (em anos anteriores a 1995 também se registraram temperaturas médias anuais na faixa dos $20^{\circ} \mathrm{C}$ ), mostrando-se favorável a reprodução do mosquito, mas nunca havia registrado casos autóctones, e consequentemente nunca registrou uma epidemia, até que em 2015 onde o ano registrou a temperatura média mais elevada da série histórica $\left(22,5^{\circ} \mathrm{C}\right)$, ouve a grande epidemia de dengue. 
Estes valores médios de temperatura para a cidade de Paranaguá mostram-se dentro da temperatura média favorável para a reprodução do A. aegypti, que varia entre $21^{\circ} \mathrm{C}$ e $29^{\circ} \mathrm{C}$, como se pode verificar em Paula (2005). Já para Castelhano et al (2012) a faixa favorável de temperatura para reprodução do mosquito vai de $19{ }^{\circ} \mathrm{C}$ a $30^{\circ} \mathrm{C}$.

Ainda sobre a variabilidade da temperatura anual, do período analisado, pode-se afirmar que há uma tendência de aumento médio principalmente nos últimos 15 a 20 anos, aumento este que também pode ser observado em Silva \& Paula (2009), em estudo de outras localidades, o que aliado ao já comentado aumento de semelhante proporção nas mínimas, pode vir a potencializar a ocorrência de casos de dengue, e possíveis novas epidemias, se a mesma se confirmar nos próximos anos.

\section{Análise mensal}

Na análise mensal dos dados, para os meses de verão (dezembro, janeiro e fevereiro), observa-se que as temperaturas médias tiveram um aumento no período analisado, apresentando os meses mais quentes fevereiro, seguido de janeiro (figura 4a, 4b, 4l). Os meses de outono (março, abril e maio), apresentaram temperaturas mais amenas com relação a estação anterior, tendo o mês de abril um aumento de temperatura mais elevado que março e maio onde mantiveram-se praticamente estáveis ao longo do período (figura $4 \mathrm{c}, 4 \mathrm{~d}, 4 \mathrm{e}$ ).

As menores temperaturas registraram-se no inverno (junho, julho e agosto), onde agosto demonstrou uma tendência de aumento mais acentuada que os demais, que se mantiveram praticamente estáveis, com o mês de julho apresentando-se o mês mais frio que todos os outros (figura $4 \mathrm{f}, 4 \mathrm{~g}, 4 \mathrm{~h}$ ).

Nos três meses da primavera (setembro, outubro e novembro), as temperaturas obtiveram aumento ao logo do período analisado. Duas médias da estação da primavera chamaram a atenção, uma por apresentar valor muito abaixo das demais, que foi em setembro de 1970 , onde ficou em $14{ }^{\circ} \mathrm{C}$, e a outra por ter apresentado valor muito acima das demais, que foi em novembro de 2009 e apresentou $25,5^{\circ} \mathrm{C}$ (figura $\left.4 \mathrm{i}, 4 \mathrm{j}, 4 \mathrm{k}\right)$. 

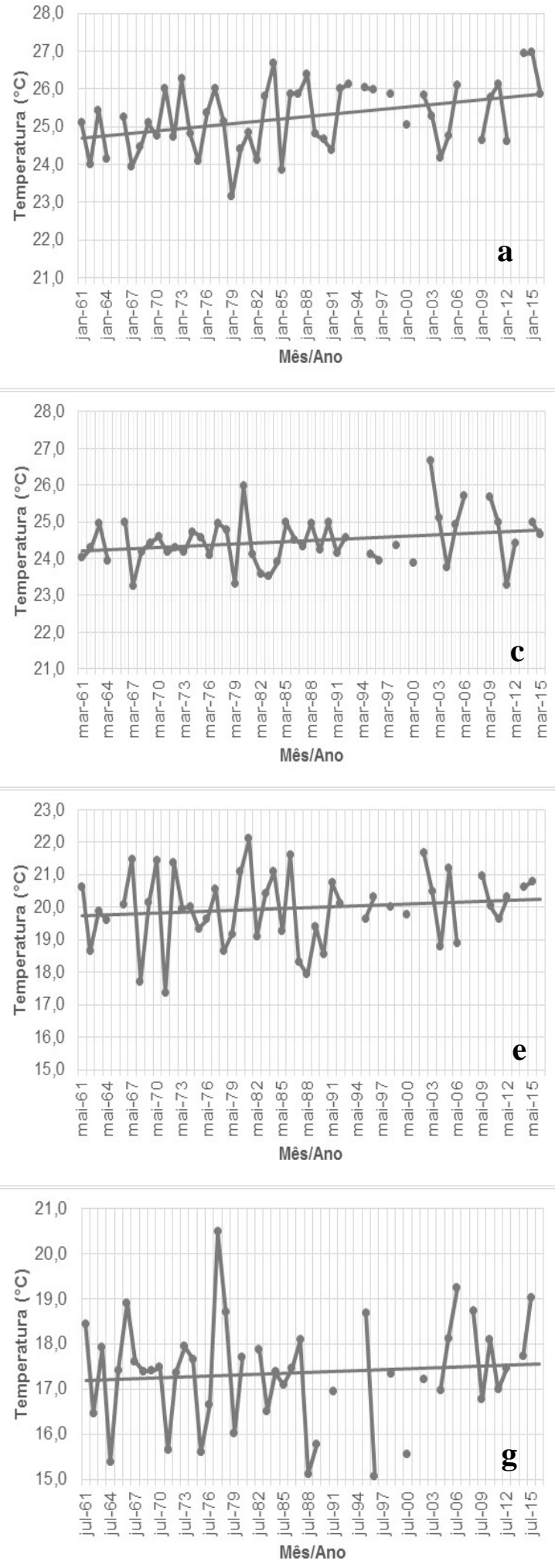
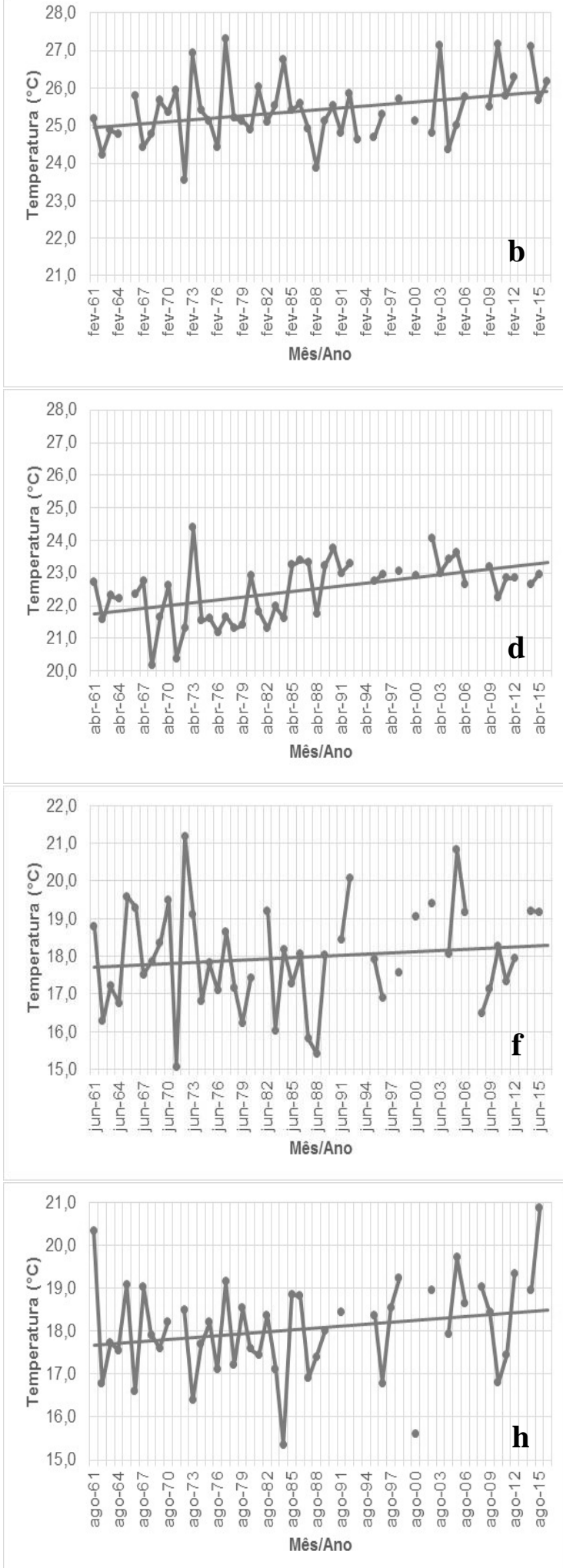

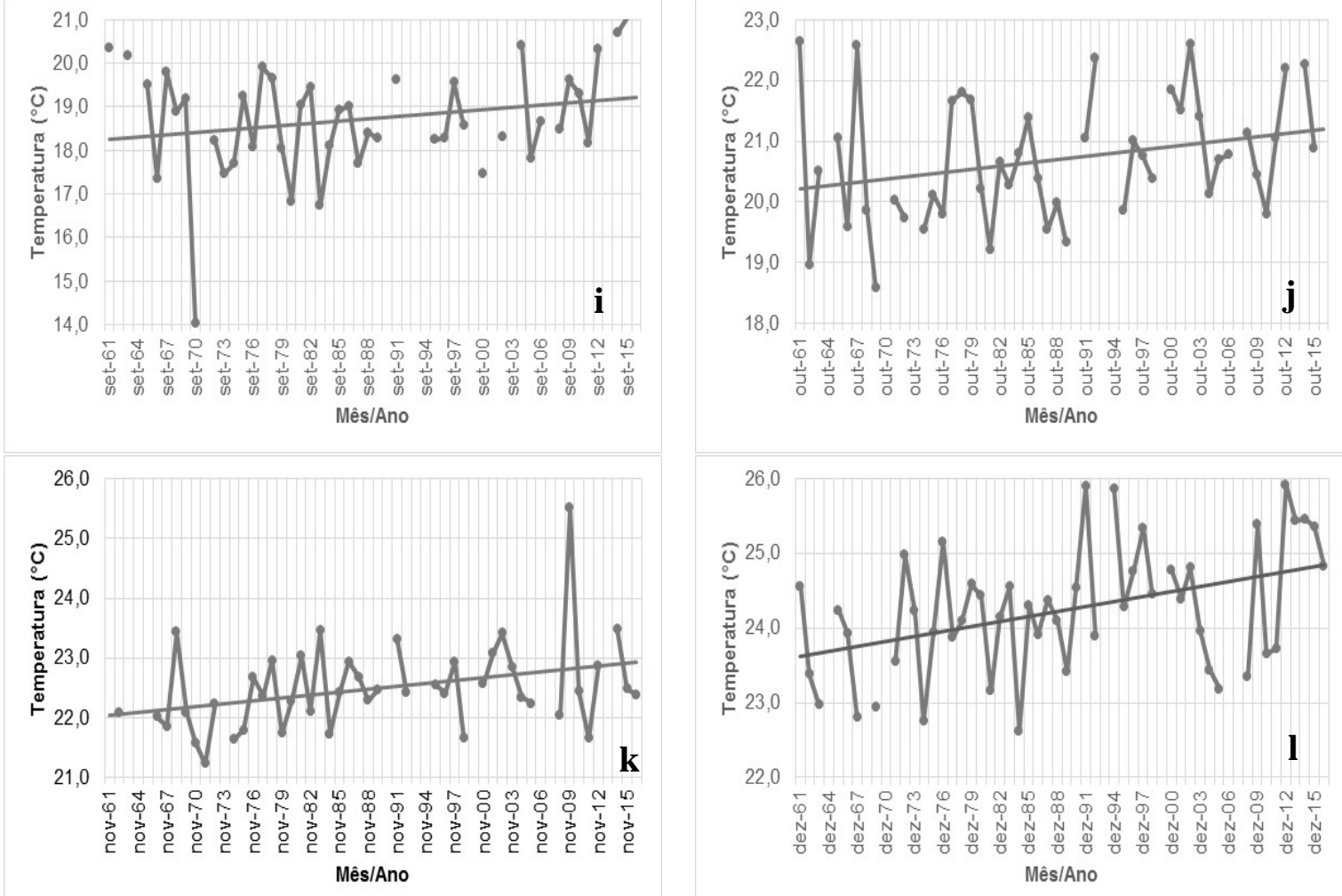

Figura 4a - 41 - Temperatura compensada média mensal $\left({ }^{\circ} \mathrm{C}\right)$ para a cidade de Paranaguá/PR no período de 1961 a 2016, a partir dados da Estação Meteorológica Convencional de Paranaguá (EMCP).

Estudos recentes sobre a dengue comprovam que o estado do Paraná passou a ter invernos mais brandos, e de curta duração, onde o período da primavera e outono, com o aumento das temperaturas nas cidades, ampliou o período mais quente do ano (JUNIOR \& MENDONÇA, 2012).

A dengue tem sua disseminação máxima nos meses mais quentes e chuvosos, compreendendo os primeiros meses do ano. Segundo Ramalho (2008), o período de maior risco de dengue no Brasil é durante ou logo após o período de chuvas, entre janeiro e março. Ao contrário, o período considerado não epidêmico por Araujo (2013), vai do final de outono até o começo da primavera.

Como já citado anteriormente, se a temperatura média mensal nos meses de inverno continuar com essa tendência de aumento dos últimos anos, os períodos mais quentes do ano vão se estender e aliados a outros parâmetros, como falta de saneamento básico, falta de ações do poder público para controle do vetor, desmatamento e ocupações irregulares, a reprodução do vetor da dengue será facilitada. Neste ponto vale ressaltar que os ovos do A. aegypti em condições desfavoráveis, como um inverno seco e 
sem chuvas, pode se tornar resistente a dessecação e sobreviver de seis meses até mais de um ano, se as temperaturas, principalmente do próprio inverno forem mais amenas, favorecendo sua sobrevivência.

No caso da epidemia de 2015 em Paranaguá, foram registrados meses com recordes de temperaturas medias, como no caso de janeiro, agosto e setembro, além de temperaturas mais amenas nos outros meses, inclusive não registrando temperaturas médias abaixo dos $19^{\circ} \mathrm{C}$ nos meses de inverno, colaborando para que o ano fosse o mais quente do período analisado.

Corroborando com os resultados obtidos na análise anual, ouve também uma tendência de aumento da temperatura mensal, principalmente nos meses de primavera e verão, juntamente com o mês de agosto, no período de inverno, dos últimos 15 a 20 anos. .

\section{Análises estatísticas}

Para finalizar as análises da série histórica de temperatura do INMET, foram os dados foram correlacionados com o Índice de Oscilação Sul (SOI), e a Temperatura do Atlântico Sul, com o objetivo de analisar e correlacionar a variabilidade climática de Paranaguá com a temperatura da superfície o mar (TSM) do Atlântico, extraída a partir dos dados do NOAA do Tropical Southern Atlantic Index (TSA) (tabela 2).

\begin{tabular}{ccccc}
\hline ANO & \multicolumn{2}{c}{ CORREL PEARSON } & \multicolumn{2}{c}{$\mathbf{R}^{\mathbf{2}}$} \\
\hline & INMET/SOI & INMET/TSA & INMET/SOI & INMET/TSA \\
$\mathbf{1 9 8 2}$ & 0,540 & 0,727 & 0,292 & 0,528 \\
$\mathbf{1 9 8 3}$ & $-0,634$ & 0,725 & 0,402 & 0,525 \\
$\mathbf{1 9 8 4}$ & 0,132 & 0,803 & 0,017 & 0,644 \\
$\mathbf{1 9 8 5}$ & $-0,320$ & 0,730 & 0,085 & 0,532 \\
$\mathbf{1 9 8 6}$ & $-0,248$ & 0,814 & 0,061 & 0,662 \\
$\mathbf{1 9 8 7}$ & 0,364 & 0,747 & 0,133 & 0,558 \\
$\mathbf{1 9 8 8}$ & $-0,292$ & 0,672 & 0,085 & 0,452 \\
$\mathbf{1 9 8 9}$ & 0,132 & 0,797 & 0,017 & 0,635 \\
$\mathbf{1 9 9 0}$ & $-0,545$ & 0,772 & 0,297 & 0,596 \\
$\mathbf{1 9 9 1}$ & 0,026 & 0,678 & 0,001 & 0,459 \\
\hline
\end{tabular}




\begin{tabular}{lclll}
\hline $\mathbf{1 9 9 2}$ & $-0,680$ & 0,780 & 0,462 & 0,608 \\
$\mathbf{1 9 9 3}$ & 0,388 & 0,740 & 0,151 & 0,547 \\
$\mathbf{1 9 9 4}$ & 0,604 & 0,738 & 0,364 & 0,545 \\
$\mathbf{1 9 9 5}$ & $-0,284$ & 0,753 & 0,080 & 0,567 \\
$\mathbf{1 9 9 6}$ & $-0,251$ & 0,712 & 0,063 & 0,507 \\
$\mathbf{1 9 9 7}$ & 0,695 & 0,730 & 0,483 & 0,532 \\
$\mathbf{1 9 9 8}$ & $-0,724$ & 0,782 & 0,525 & 0,612 \\
$\mathbf{1 9 9 9}$ & 0,738 & 0,784 & 0,545 & 0,615 \\
$\mathbf{2 0 0 0}$ & 0,510 & 0,753 & 0,260 & 0,567 \\
$\mathbf{2 0 0 1}$ & 0,546 & 0,752 & 0,298 & 0,566 \\
$\mathbf{2 0 0 2}$ & 0,507 & 0,812 & 0,257 & 0,659 \\
$\mathbf{2 0 0 3}$ & $-0,015$ & 0,802 & 0,000 & 0,643 \\
$\mathbf{2 0 0 4}$ & 0,024 & 0,714 & 0,001 & 0,510 \\
$\mathbf{2 0 0 5}$ & $-0,398$ & 0,892 & 0,159 & 0,796 \\
$\mathbf{2 0 0 6}$ & 0,744 & 0,782 & 0,554 & 0,612 \\
$\mathbf{2 0 0 7}$ & $-0,034$ & 0,795 & 0,001 & 0,632 \\
$\mathbf{2 0 0 8}$ & 0,591 & 0,724 & 0,349 & 0,524 \\
$\mathbf{2 0 0 9}$ & 0,265 & 0,671 & 0,070 & 0,450 \\
$\mathbf{2 0 1 0}$ & $-0,649$ & 0,810 & 0,421 & 0,656 \\
$\mathbf{2 0 1 1}$ & 0,809 & 0,734 & 0,655 & 0,539 \\
$\mathbf{2 0 1 2}$ & 0,433 & 0,683 & 0,187 & 0,466 \\
$\mathbf{2 0 1 3}$ & $-0,399$ & 0,730 & 0,159 & 0,532 \\
$\mathbf{M E D}$ & $\mathbf{0 , 0 8 0}$ & $\mathbf{0 , 7 5 4}$ & $\mathbf{0 , 2 3 2}$ & $\mathbf{0 , 5 7 1}$ \\
\hline $\mathbf{P e}$ & $\mathbb{2 0 0}$ & & \\
\hline
\end{tabular}

Tabela 2. Correlações Pearson e $\mathrm{R}^{2}$ entre os dados do INMET, SOI e TSA para a cidade de Paranaguá/PR no período de 1982 a 2013

Na comparação INMET/TSA (TSA com dados apenas do período de 1982 à 2013), é observada uma forte relação entre os dados, apresentando valores acima de 0,7 conforme tabela 1 . Deste modo, observa-se que a temperatura da cidade de Paranaguá é influenciada diretamente pela variabilidade da TSM do Atlântico Sul.

Também é importante destacar a elevada correlação média para o período analisado (1982-2013) entre os dados do INMET e TSA, mostrando tanto através de Pearson quanto $\mathrm{R}^{2}$ que a temperatura do Atlântico tem influência significativa na variabilidade da temperatura de Paranaguá, embora nos anos de El Niño mais intenso os valores de SOI também apresentem correlação significante.

Estas análises, bem como análises futuras a partir deste estudo, são importantes para buscar entendermos um pouco mais da dinâmica climática da região, pois se tratando de uma cidade litorânea 
não basta estudar somente a relação entre ação antrópica versus ação da temperatura local, necessitando ter o conhecimento também de eventos climáticos de maior proporção, que possam vir a influenciar direta ou indiretamente no clima e temperatura da cidade, favorecendo consequentemente a proliferação de vetores, como é o caso do vetor da dengue.

\section{CONSIDERAÇÕES FINAIS}

A dengue é uma das doenças tropicais que mais atinge a população mundial, e com o aumento da temperatura em nível global, está cada vez mais frequente. No Brasil não é diferente, nos últimos anos epidemias de dengue estão cada vez mais frequentes e com intervalos entre elas cada vez menores.

No estado do Paraná, a grande maioria das cidades já registraram casos de dengue, e algumas como Foz do Iguaçu, Maringá e Londrina, vem enfrentando esse problema com maior frequência nas últimas duas décadas. E outras, como a cidade de Paranaguá, que enfrentou uma grande epidemia no ano de 2015, teve seus primeiros registros endêmicos da doença, o que motivou o presente estudo.

A análise dos dados da temperatura nos últimos 55 anos para a cidade de Paranaguá, demonstrou um aumento médio de $0,8^{\circ} \mathrm{C}$, estando dentro da previsão da média global, porém apresentando um aumento mais evidente tanto na média anual quanto na média para alguns meses (principalmente os meses de verão), mais acentuada nos últimos 15 anos. Em contrapartida nos meses de inverno, considerados meses chave para uma possível ocorrência de epidemia, já que se houver um inverno com temperaturas mais elevadas, o mosquito terá mais chances de sobrevivência, não houve aumento significativo ao longo do período analisado, exceto no mês de agosto.

Embora os anos de 2014 e 2015 tenham contribuído para a epidemia de dengue, devido a ser os dois anos mais quentes na média anual $\left(22,5^{\circ} \mathrm{C}\right)$, e também em alguns meses batendo recordes, inclusive com os meses de inverno entre os mais quentes, não é possível afirmar que a temperatura sozinha é a grande responsável pela ocorrência da epidemia, já que anos anteriores também se mostraram 
propícios a apresentar casos de dengue, podendo-se citar anos como $1961\left(22,1^{\circ} \mathrm{C}\right), 1977\left(22,2^{\circ} \mathrm{C}\right)$, $1981\left(22,1^{\circ} \mathrm{C}\right)$ e $2002\left(22,3^{\circ} \mathrm{C}\right)$, que ficaram muito próximos da média de 2014 e 2015.

É inegável de acordo com os resultados obtidos que nos últimos 55 anos de dados disponíveis, a cidade de Paranaguá vem sofrendo um aumento de temperatura, mas não significa que este aumento sozinho é o responsável, em especial pela epidemia de dengue ocorrida em 2015 na cidade. Outros fatores que podem ter contribuído, e que foram citados por promotores do Ministério Público em entrevista ao jornal Gazeta do Povo (2016), e que vale ressaltar aqui são: Número insuficiente de agentes de saúde no combate aos focos do mosquito; Problemas de saneamento básico; Ocupações irregulares ocasionadas pela devastação da mata atlântica, que modificou o ambiente natural de ocorrência do mosquito, facilitando assim sua instalação.

Tomando como base, este estudo visa servir como embasamento teórico para estudos futuros, sendo necessário acompanhar essa tendência de aumento na temperatura na cidade de Paranaguá pelos próximos anos. Também é interessante que em estudos futuros sejam inclusos análises de outros fatores que envolva a questão socioambiental, que possam contribuir para novos casos da doença e possíveis epidemias, para assim se ter uma noção exata da(as) real(is) causa(as) dos casos de dengue na cidade de Paranaguá/PR.

\section{REFERÊNCIAS}

ARAUJO, W. M. Políticas públicas de controle da dengue no estado do Paraná: uma abordagem geográfica. 125 f. Dissertação (Mestre em Geografia) - Setor de Ciências da Terra, Universidade Federal do Paraná, Curitiba, 2013.

BIANCHIN, J. E. Aporte de fitomassa e nutrientes em florestas secundárias da Mata Atlântica no litoral do Paraná. 102 f. Dissertação (Mestre em Engenharia Florestal) - Setor de Ciências Agrárias, Universidade Federal do Paraná, Curitiba, 2013.

CONTI, J. B. Considerações sobre as mudanças climáticas globais. Revista do Departamento de Geografia, v. 16, p. 70-75, 2005.

BIGARELLA, J. J. 1947. Contribuição ao estudo da planície litorânea do Estado do Paraná. Brazilian Archives of Biology and Technology, p. 65-110, dez. 2001. 
BORDIN, L. B. Epidemia de dengue em Paranaguá era "tragédia anunciada", diz MP. Gazeta do Povo, Curitiba. 30/05/2016. Acesso em: http://www.gazetadopovo.com.br/vida-e-cidadania/epidemia-de-dengue-em-paranagua-eratragedia-anunciada-diz-mp-7s0mh54abht55t5kl0qypxpu1. Acesso em 25 fev. 2018.

CATÃO, R. C. DENGUE NO BRASIL: Abordagem geográfica na escala nacional. 169 f. Dissertação (Mestrado em Geografia) - Programa de Pós-Graduação em Geografia da FCT/UNESP, Universidade Estadual Paulista, Presidente Prudente, 2011.

CASTELHANO, F. J.; ROSEGHINI, W. F. F. MENDONÇA, F. Clima urbano e dengue: uma introdução a partir da análise do campo térmico de Maringá/PR e Campo Grande/MS. Revista Geonorte, v. 2, n. 5, p. 735-748. 2012.

DUQUE J. E. L., DA SILVA R. V.; KUWABARA E. F.; SILVA M. A. N. Dengue no estado do Paraná, Brasil: distribuição temporal e espacial no período 1995-2007. Revista Salud Uis, v. 42, p. 113-122, ago. 2010.

FERREIRA, H. H. Análise espacial dos casos de Aedes aegypti e sua relação com o meio ambiente urbano. $37 \mathrm{f}$. Dissertação (Mestrado em Ciências Ambientais) - Universidade Estadual Paulista, Sorocaba, 2016.

HONÓRIO, N. A. et al. The spatial distribution of Aedes aegypti and Aedes albopictus in a transition zone, Rio de Janeiro, Brazil. Caderno de Saúde Pública, Rio de Janeiro, v. 25, n. 6, p. 1203-1214, jun. 2009.

IPCC: Summary for Policymakers. In: Climate Change: The Physical Science Basis. Contribution of Working Group I to the Fifth Assessment Report of the Intergovernmental Panel on Climate Change [Stocker,T.F., D. Qin, G.-K. Plattner, M. Tignor, S.K. Allen, J. Boschung, A. Nauels, Y. Xia, V. Bex and P.M. Midgley (eds.)]. Cambridge University Press, United Kingdom and New York, NY, USA. 2013.

JUNIOR, J. A.; MENDONÇA, F. A. A problemática da dengue em Maringá-PR: Uma abordagem socioambiental a partir da epidemia de 2007. Revista Brasileira de Geografia Médica e da Saúde, v. 8, n. 15 p. 157-176, dez. 2012.

MELLO, Y. R.; LOPES, F. C. A.; ROSEGHINI, W. F. F. Características climáticas e análise rítmica aplicada a episódios extremos de precipitação e temperatura no município de Paranaguá, PR. Revista Brasileira de Climatologia, v. 20, n. 13, p. 313-336, jan./jul. 2017.

MELO, D. P. O. Análise espacial e temporal da distribuição de casos de dengue e do monitoramento de Aedes aegypti (Diptera: Culicidae) em duas regiões de Belo Horizonte (MG): Influências das variáveis climáticas e das intervenções para controle do vetor. 186 f. Dissertação (Mestrado em Parasitologia) - Departamento de Parasitologia, Universidade Federal de Minas Gerais, Belo Horizonte, 2009.

MENDONÇA, F. A.; SOUZA, A. V.; DUTRA, D. A. Saúde pública, urbanização e dengue no Brasil. Revista Sociedade \& Natureza, Uberlândia, v. 21, n. 3, p. 257-269, dez. 2009.

PAULA, E. V. Evolução espaço-temporal da dengue e Variação termo-pluviométrica no Paraná: Uma abordagem geográfica. R. RA'E GA, Editora UFPR, n. 10, p. 33-48. 2005.

Primeiro relatório do Painel Brasileiro de Mudanças Climáticas (PBMC, 2015). Acesso em: http://www.pbmc.coppe.ufrj.br/pt/noticias/82-destaque/440-painel-brasileiro-de-mudancas-climaticas-divulga-o-primeirorelatorio-de-avaliacao-nacional-completo. Acesso em 10 out. 2018.

RAMALHO, W. M. Influência das alterações climáticas nos casos de dengue nos anos de 2007 a 2011 no município de Cascavel-PR. 121 f. Dissertação (Mestrado em Saúde Coletiva) - Setor de Pós-Graduação em Saúde Coletiva, Universidade Federal da Bahia, Salvador, 2008.

SECRETARIA DA SAÚDE DO ESTADO DO PARANÁ (SESA). Acesso em: http://www.saude.pr.gov.br/ . Acesso em 17 out. 2018 . 
SEREDA, F. Caracterização nutricional e grau de esclerofilia foliar de Guanandi em Floresta Ombrófila Densa no litoral do Paraná. 80 f. Dissertação (Mestrado em Ciências do Solo) - Setor de Ciências Agrárias, Universidade Federal do Paraná, Curitiba, 2008.

SILVA, R. W. C.; PAULA, B. L. Causa do aquecimento global: Antropogênica versus natural. Revista Terra e Didática, v. 5, n. 1, p. 42-49, 2009 .

VANHONI, F.; MENDONÇA, F. O clima do litoral do estado do Paraná. Revista Brasileira de Climatologia, v. 3 e 4, p. 50 63 , ago. 2008. 